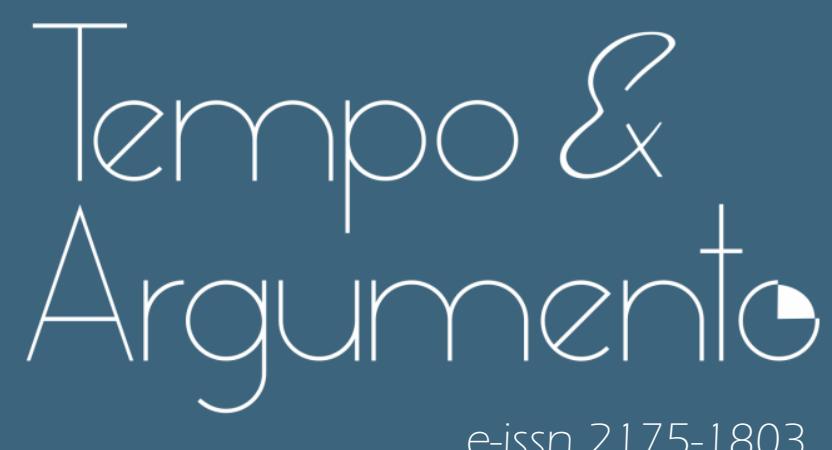

e-issn 2175-1803

\title{
Direitos humanos no Brasil democrático - trajetória e perspectivas: 1988/2019
}

- Rivail Carvalho Rolim

Doutor em História pela Universidade Federal Fluminense (UFF).

Estágio Pós-Doutoral no Observatório do Sistema Penal e Direitos Humanos,

da Universidade de Barcelona, com bolsa Capes.

Professor da Universidade Estadual de Londrina (UEL).

Londrina, PR - BRASIL

lattes.cnpq.br/0342145909258572

rivailrolim@uel.br

(D) orcid.org/0000-0002-3048-7978

Para citar este artigo:

ROLIM, Rivail Carvalho. Direitos humanos no Brasil democrático - trajetória e perspectivas: 1988/20 19. Tempo e Argumento, Florianópolis, v. 12, n. 30, e0206, maio/ago. 2020.

doi http://dx.doi.org/10.5965/2175180312302020e0206

Recebido: 02/12/2019

Aprovado: 28/05/2020 


\title{
Direitos humanos no Brasil democrático - trajetória e perspectivas: 1988/2019
}

\begin{abstract}
Resumo
No último meio século ocorreram profundas mudanças sociais nos principais países ocidentais, com reflexos significativos no Brasil. Essas transformações têm impactado a vivência dos direitos humanos nesses países e afetado a concretização de um estado democrático de direito em nosso país e, até mesmo, provocado alguns retrocessos. Este artigo tem como objetivo fazer uma reflexão sobre a trajetória e as perspectivas do ideário dos direitos humanos na sociedade brasileira para delinearmos melhor o que o tempo presente pode revelar de ruptura, de descontínuo e de início. Neste trabalho, voltaremos nossas atenções para os direitos civis, particularmente os direitos à vida, à integridade física, à justiça e o enfrentamento da impunidade dos crimes cometidos por agentes do Estado.
\end{abstract}

Palavras-chave: Direitos Humanos. Violência. Repressão Policial.

\section{Human rights in democratic brazil: trends and perspectives between 1988 and 2019}

\begin{abstract}
Deep social changes have occurred in the main Western countries during the last fifty years, with significant effects on Brazil. Transformations have impacted the experience of human rights in these countries and affected the materialization of the democratic state in the country, coupled to several backward stances. Current paper analyzes the trajectory and perspectives of human rights so that rupture, discontinuity and the start in Brazilian society reveal and may be currently traced. This paper, we will turn our attention to civil rights, particularly the rights to life, physical integrity, justice and the impunity of crimes committed by State agents.
\end{abstract}

Keywords: Human rights. Violence. Police repression. 
Nesta reflexão, procuramos vislumbrar com mais atenção o cenário social de profundas mudanças sociais nos principais países ocidentais e seus reflexos no Brasil, com a intenção de deslindar alguns acontecimentos e processos históricos que estão moldando o tempo presente. As transformações que ocorreram no último meio século têm impactado a vivência dos direitos humanos, no âmbito dos direitos civis e individuais, nesses países e afetado a consolidação de um estado democrático de direito em nosso país e, até mesmo, provocado alguns retrocessos.

Quando da promulgação da Declaração Universal dos Direitos Humanos, em 1948, alguns direitos considerados inalienáveis e universais, como os direitos civis e individuais, nas últimas décadas, começaram a ser questionados tanto nos países centrais do capitalismo, quanto em nações que procuraram mais tardiamente incorporar esses princípios como marco de referência política, legal e cultural, caso do Brasil com a democratização após o fim do regime militar. 0 princípio de que "sem direitos do homem reconhecidos e efetivamente protegidos não existe democracia, sem democracia não existem as condições mínimas para a solução pacífica dos conflitos", conforme defendia Norberto Bobbio (2004, p. 203) no início da década de 1990, começa a ser vilipendiado.

O Brasil, que adotou os direitos humanos como política de Estado após o fim da ditadura militar, ratificando inúmeros tratados internacionais, tem se deparado com duros ataques, e por consequência, retrocessos significativos nos últimos anos. A impressão é de que saímos da euforia sobre a possibilidade real e concreta de construirmos uma sociedade livre, justa e solidária imediatamente após 1988, para outra, que ataca de forma contundente esses princípios e postulados. Talvez a empatia, muito bem discutida por Lynn Hunt (2009), que foi gerada em torno da defesa dos direitos humanos na conjuntura de democratização do país, que levou a formulação dos PNDHs, esteja se esvaindo.

Como estamos passando por grandes mudanças sociais em relação à vivência dos direitos humanos em um curto espaço de tempo, as quais têm impactado nossas vidas, temos a necessidade de construir alguma explicação para encontrarmos algumas respostas, mesmo que não sejam definitivas, todavia, que se fazem necessárias. Nesse sentido, Agnès Chauveau e Philippe 
Tétart (1999, p. 16) destacam que os historiadores não têm se recusado mais a trabalhar os acontecimentos que estão vivendo. Além disso, entendemos que "uma reflexão histórica sobre o presente pode ajudar as gerações que crescem a combater a atemporalidade contemporânea [...] a se desfazer desse imediatismo vivido que aprisiona a consciência histórica." (RIOUX, 1999, p. 46).

Desenvolveremos as reflexões em torno do tema direitos humanos, mais detidamente, sobre o direito à vida, à integridade física, à justiça e o enfrentamento da impunidade dos crimes cometidos por agentes do Estado, com a concepção teórica de que "a história não é somente estudo do passado, ela também pode ser, com um menor recuo e métodos particulares, o estudo do presente." (CHAVEAU; TETART, 1999, p. 15). Abordar, portanto, o tema dos direitos humanos, no âmbito dos direitos civis e individuais, nessa perspectiva, possibilita delinearmos melhor o que o presente pode revelar de descontínuo, de ruptura e de início, no que diz respeito às condições para a interrupção ou continuidade das práticas ilegais e violentas de resolução de conflitos.

Para o encaminhamento dessa reflexão utilizamos como fontes de pesquisa os principais documentos legais, como a Constituição de 1988 e os três Planos Nacionais de Direitos Humanos - PNDHs, promulgados, respectivamente em 1996, 2002 e 2009. Tais documentos foram fundamentais para se entender como foi sendo pensada a constituição de uma ordem social, que vislumbrava incorporar os direitos humanos na cultura política nacional. Por intermédio deles, foi possivel identificar as intenções para se estruturar um país que tivesse como horizonte o respeito aos direitos civis e individuais.

Entretanto, como salienta Pierre Rosanvallon (2010), não se pode ficar restrito às formulações dos documentos legais para se entender a construção da ordem social brasileira. Nesse sentido, a imprensa escrita, principalmente os jornais de grande circulação nacional, foram fundamentais, pois deram ampla cobertura ao tema, inclusive, mostrando como foram recepcionados pelos mais variados segmentos sociais, os documentos legais promulgados. Algumas matérias produzidas por blogues contribuíram para confrontarmos informações, o que permitiu uma melhoria na reflexão. Vale destacar que já foram superados 
os receios e preconceitos quanto a esse tipo de documento, passando-se a reconhecer a importância da imprensa nos estudos históricos (CAPELATO, 1980).

Ao se tratar mais especificamente sobre o uso da imprensa escrita, primeiramente não se pode considerá-la com uma fonte precisa, em que a informação vale por si mesma, porque sempre age no campo político-ideológico, logo, organiza as informações ou os acontecimentos que devem se transformar em notícia, em reportagem ou mesmo em editorial, seguindo seu próprio filtro. A análise não deve se basear somente nos aspectos quantitativos, na frequência de aparição das notícias, mas sim em indicadores não frequenciais suscetíveis de permitir inferências. Por exemplo, é importante assinalar como certas noções ou palavras começam a aparecer com mais frequência ou até mesmo mudam de sentido ao longo de um determinado período, como os direitos humanos, foco desta reflexão (BARDIN, 2011).

Além desse corpus documental, foi fundamental também recorrer aos relatórios da Human Watch Rights, Centro de Justiça Global e a Anistia Internacional. Nos últimos anos, essas ONGS ganharam ainda mais relevância, tanto no âmbito nacional quanto internacional, produzindo relatórios detalhados sobre discriminação, tortura, abusos do sistema judicial, violência policial ou violação das leis do direito humanitário internacional. Com isso, constituíram um corpus documental importante acerca do tema que nos propusemos a analisar.

\section{a) Os direitos humanos e os países centrais do capitalismo}

Para se tratar dos direitos humanos no âmbito dos direitos civis e individuais, especificamente sobre a repressão e a violência por parte do aparato estatal, na sociedade brasileira no tempo presente é necessário entender as grandes transformações que aconteceram nos principais países ocidentais nos últimos 50 anos. Vivemos em um mundo globalizado cujas experiências históricas que têm ocorrido no espaço do Atlântico Norte se reproduzem em outras realidades sociais. O Brasil, por exemplo, não ficou indiferente a essas mudanças, e ideias como neoliberalismo, globalização, tolerância zero, cárcere duro, direitos humanos, mas também a intensificação da repressão e uso da 
violência por parte do Estado como política de segurança pública foram apropriadas pelo ideário político de nosso país.

Ao se utilizar os instrumentos de trabalho, que criam em todos os lugares e por todo o tempo o famoso recuo, para recorrermos às palavras de Jean-Pierre Rioux (1999, p. 46), no último meio século o mundo ocidental do Atlântico Norte passou por intensos questionamentos ao estado de bem-estar social que se consolidara após a Segunda Guerra Mundial. Os países da social democracia, segundo Tony Judt (2015, p. 62), viveram "numa era tranquila e de segurança próspera: uma bolha, talvez, mas uma bolha reconfortante em que muitas pessoas se saíram bastante melhor do que poderiam imaginar no passado e, tinham boas razões para antever o futuro com confiança”. Nesse cenário, o entendimento era de que a prosperidade econômica diminuiria consideravelmente os problemas sociais relacionados a crime, saúde, educação, emprego e pobreza. Para aqueles que não fossem equacionados com a própria melhora da economia, haveria uma intervenção racionalizada do Estado, ou seja, a adoção de políticas públicas que permitiriam a integração das pessoas na vida social.

O estado social-democrata procurou, portanto, seguir o postulado de garantir bem-estar às pessoas e recuperar aquelas que não haviam se integrado. O entendimento era de que a resposta para os problemas sociais passava pela combinação de trabalho social e de reforma social realizada de maneira profissional pelos órgãos públicos. Para efeito comparativo, na Inglaterra do pósguerra, o ideário político era de que "os serviços sociais públicos deviam ser encarados como uma parcela permanente da cultura nacional de que o povo devia orgulhar-se" (MARSHALL, 1967, p. 122). Quanto a esse ideário político, Garland (2008, p. 121) assinala: "para intelectuais mais conservadores, o estado de bem-estar social era o preço que se deveria pagar pela paz social, pela estabilidade econômica e pela educação adequada e treinamento da força de trabalho". Hobsbawm (2012) chegou a se referir a esse período como "anos dourados" ou os "trinta anos gloriosos".

No entanto, ao longo da década de 1970, esse estado de bem-estar social passou a ser visto como impagável, oneroso, e seus custos deveriam ser 
reduzidos drasticamente, pois poderiam comprometer o próprio funcionamento do Estado e a dinâmica da vida social. Como ressalta Ignácio Sotelo (2010, p. 271), para o Fundo Monetário Internacional, não havia outro remédio a não ser "reduzir drasticamente os custos, suprimindo serviços e eliminando a burocracia". De maneira concomitante, as políticas públicas do estado de bem-estar social passaram a ser duramente atacadas, com o argumento de que o poder estatal não tinha capacidade de atender as demandas oriundas da sociedade, seja de grupos sociais específicos ou indivíduos, porque eram ineficientes e contraproducentes.

A presença do Estado em vários âmbitos da vida social passou a ser concebida como algo discricionário e invasivo, pois afetava a autonomia do indivíduo. No ideário político-econômico, Friedrich Hayek (2010) pontuava que o controle planejado das atividades, como faziam os regimes sociais democratas, levava necessariamente ao comando da própria existência humana. Nesse livro, que se transformou em catecismo da nova direita nos anos 1970, o economista compara o estado social-democrata com os regimes nazista e comunista, pois, de acordo com sua opinião, a planificação econômica levava o ser humano à escravidão.

A justiça criminal/penal foi qualificada de ineficiente. A noção de que "nada funciona" ou "nothing works" se disseminou como um rastilho de pólvora. Aliado a isso, cresceram consideravelmente os grupos políticos e da sociedade civil que defendiam abertamente a adoção de penas mais duras e ações repressivas mais rigorosas, como a política criminal "broken windows", "three strikes and you're out", "lock' em up and throw away the key" e "zero tolerance", para lidar com aqueles que eram capturados (dragged) pelas agências estatais. Como sinaliza David Garland (2008), cresceu o movimento político que defendia como solução a intimidação, o controle e a repressão, ao invés de mais bem-estar social.

No bojo da implantação das políticas neoliberais, a tentação penal também chegou à Europa, apesar de que, em menor escala. Na França, "o zelo policial e o rigor penal se transformaram em fortes argumentos eleitorais e até em dogma político" (WACQUANT 2004, p. 216). Na Itália, Alessandro De Giorgi (2005, p. 97) aponta para um "funcionamento seletivo dos aparatos de repressão e controle 
social", pois ocorre não em função de um comportamento que determina a sanção penal, mas sim devido a uma presunção de periculosidade do imigrante enquanto tal. Não podemos esquecer a compreensão do risco criminal presente em todas as disposições do Tratado de Schengen:

Uma concepção de periculosidade e de risco criminal que ignora os indivíduos, as situações culturais, sociais e familiares e de cada um, para tratar o problema em termos de categorias, populações e grupos sociais, cuja definição negativa se baseia em parâmetros diferentes aos normalmente aplicados aos residentes. (DE GIORGI, 2005, p. 104)

Diante dessas transformações, o definhamento do Estado socialdemocrata correspondeu ao crescimento vertiginoso do Estado penal, ou seja, a miséria e a extinção de um, teve como contrapartida direta o crescimento do outro. Os Estados Unidos são "cinco vezes mais punitivos hoje do que há um quarto de século" (WACQUANT, 2008, p. 09). Quanto à Europa, mais especificamente a França, a "luta contra a delinquência como um espetáculo permanente permitiu aos dirigentes atuais reafirmar simbolicamente a autoridade do Estado no momento exato em que se percebe sua impotência no campo econômico e social” (WACQUANT, 2004, p. 217).

Na condução de suas pesquisas, Loic Wacquant (2009) e David Garland (2008) frisaram que se constituiu uma nova cultura do controle do crime com a criminalização da miséria e a adoção de uma estratégia de grande confinamento. Acerca dessa questão, não podemos deixar de fazer referência a Nils Christie (1993, p. 21), para quem o setor carcerário acabou por se constituir em uma indústria com uma condição privilegiada, pois não havia escassez de matériaprima, já que as demandas por segurança cresciam a cada dia.

Como resultado dessas profundas mudanças sociais, com o avanço das políticas neoliberais, entramos no século XXI com uma ordem social marcada pelo avanço do desrespeito aos direitos humanos - civis e individuais - nos principais países ocidentais. No espaço do Atlântico Norte, cada vez mais foram ganhando força ações governamentais que colocavam em xeque uma cultura política democrática e de respeito ao estado de democrático de direito. Os postulados contidos na Declaração Universal dos Direitos Humanos, de 1948, 
concebidos, inclusive, como pertencentes aos valores da civilização jurídica moderna, na atualidade não são vistos mais em uma perspectiva igualitária e universalista, mas a partir de comunidades etnicamente homogêneas, tanto na Europa quanto nos Estados Unidos. Algumas lideranças políticas, como o primeiro ministro dinamarquês Soren Pind, não se sentem constrangidas de admitir publicamente que "seu país é uma tribo que descende dos vikings, e que por isso é tão difícil absorver imigrantes, sobretudo não-ocidentais" (É PRECISO..., 2011, p. 1).

Nos Estados Unidos, o relatório da Human Rights Watch (2005a) informava que cada vez mais estavam sendo utilizados interrogatórios mediante coação, detenções arbitrárias e brutalidade policial para grupos sociais pauperizados. Quanto aos estrangeiros, houve uma recusa em se aplicar leis de guerra e normas de direitos humanos às pessoas acusadas de terrorismo, além de impedir que desfrutassem de garantias processuais fundamentais quando fossem detidas por ordem presidencial acusadas de inimigas. O governo Bush (2001/2009), em sua estratégia antiterrorista, procurou aumentar o poder do executivo para ações sem supervisão judicial e legislativa. Essas medidas antiterroristas tiveram implicações significativas tanto para os estrangeiros como para os cidadãos estadunidenses, haja vista as constantes violações das garantias processuais no sistema de justiça penal (HUMAN WATCH RIGHTS, 2005a).

Esse mesmo relatório apontou que os governos da Europa reduziram drasticamente as salvaguardas, principalmente daqueles que solicitavam asilo ou eram refugiados. Os atentados de 11 de setembro de 2001 - EUA - e 11 de março de 2004 - Espanha - acabaram sendo utilizados para justificar políticas de exclusão, como etiquetar os imigrantes de terroristas ou perigosos para a segurança nacional. Os países do bloco também passaram a aplicar estratégias antiterroristas que violam os direitos fundamentais, como detenção indefinida de estrangeiros suspeitos de terrorismo, detenção incomunicável por um período e flexibilização da proibição absoluta do uso da tortura (HUMAN WATCH RIGHTS, 2005b). Quanto às migrações, foi desencadeada uma luta contra os ilegais ( sanspapier, sin papeles), refletindo o pressuposto de que eles não têm a mesma condição jurídica dos europeus. Consta nesse documento que as ações de 
"securitização da imigração" ocorreram com grave prejuízo dos direitos dos imigrantes. Alguns países do bloco argumentam que vivem em uma situação de emergência; com isso, defendem o abandono de algumas obrigações consideradas fundamentais em matéria de direitos humanos (HUMAN WATCH RIGHTS, 2005b).

A eleição de Donald Trump nos Estados Unidos agudizou ainda mais a situação de parcelas vulneráveis da população. No relatório da Human Watch Rights (2019a) consta que o governo estadunidense implementou uma série de políticas anti-imigração, coibiu as iniciativas para se reduzir as altas taxas de encarceramento, realizadas no Governo de Barak Obama (2009/2016), e contribuiu para enfraquecer o programa de seguridade social. As prisões federais e estaduais ainda mantêm mais de 2 milhões de pessoas encarceradas, e outros 4,5 milhões em regime condicional. A taxa de encarceramento de mulheres aumentou mais de $700 \%$ ao longo de 30 anos. As disparidades raciais perpassam o sistema de justiça penal-criminal dos EUA, haja vista que os negros são 13\% da população, porém representam cerca de 40\% da população prisional. Com isso, a taxa de encarceramento de negros é cinco vezes maior que a de pessoas brancas (HUMAN WATCH RIGHTS, 2019a).

Em relação ao continente europeu, partidos de extrema-direita passaram, nos últimos anos, a exercer grande influência política. O relatório da Human Watch Rights (2019b) sobre o ano de 2018, informa que a Comissão Europeia tem se deparado com várias situações em que países pertencentes ao bloco querem elaborar leis para enfraquecer ou ameaçar a independência do poder judicial do país. A França, por exemplo, endureceu ainda mais as leis de imigração e asilo. Não é sem sentido que houve denúncias de que os imigrantes vivem em condições deploráveis nos acampamentos. O mais conhecido deles, o de Calais, chegou a ser denominado "a selva", devido as suas más condições (HUMAN WATCH RIGHTS, 2019b).

Vivenciamos, portanto, um cenário de retrocessos consideráveis dos princípios e postulados dos direitos humanos, no âmbito dos direitos civis e individuais, nos principais países ocidentais nas últimas décadas. Luigi Ferrajoli (2010, p. 15), jurista italiano, reconhecido expoente do garantismo jurídico, declara 
que "estamos assistindo, inclusive nos países de democracia mais avançada, a uma crise profunda e crescente do direito, que se manifesta em diversas formas e em múltiplos planos".

\section{b) Os direitos humanos no Brasil democrático}

Diante desse cenário de grandes transformações no mundo ocidental, desse mundo que não fazemos ideia do que os nossos filhos irão herdar, para recorrermos às palavras de Tony Judt (2015), que o Brasil iniciou sua transição política, culminando com a promulgação da Constituição de 1988, chamada de constituição cidadã. Dentre os fundamentos constitucionais, destacamos a intenção de construir uma sociedade livre, justa e solidária (BRASIL, 1988, art. 3, I); erradicar a pobreza e a marginalização, reduzir as desigualdades sociais e regionais (BRASIL, 1988, art. 3, III); promover o bem de todos, sem preconceitos de origem, raça, sexo, cor, idade e quaisquer outras formas de discriminação (BRASIL, 1988, art. 3, IV).

Com esses preceitos constitucionalizados, a "cidadania, literalmente, caiu na boca do povo", para recorrermos a José Murilo de Carvalho (2005, p. 7). Contudo, o caminho para a efetivação dos direitos civis e individuais, o controle da violência estatal, que estavam enunciados na Constituição, não seria nada simples em função de dois aspectos expressivos. A nova racionalidade punitiva e repressiva, o ideário neoliberal e conservador, que ganhou força nessa conjuntura nos principais países ocidentais, entrelaçados com situações concretas de discriminação, exclusão social, violência legal e ilegal por parte do aparato estatal em relação a grupos pauperizados presentes na trajetória histórica da sociedade brasileira, enfraqueceriam as ações que procuravam efetivar os direitos civis e individuais para a maioria da população.

$\mathrm{Na}$ realidade, uma política criminal intensificada durante os governos militares de que os "inimigos" deveriam ser combatidos ficou quase intocada, mesmo com a transição política para a democracia. Segundo Paulo Sérgio Pinheiro (1991), as ações do aparato repressivo, que estiveram sempre caracterizadas por um alto nível de ilegalidade na trajetória do regime republicano, independente da vigência ou não das garantias constitucionais, 
continuaram ser a pedra de toque, mesmo com o fim do regime militar. Acrescenta ainda, de modo incisivo, que "para os pobres, miseráveis e indigentes que sempre constituíram a maioria da população podemos falar de um ininterrupto regime de exceção paralelo, sobrevivendo às formas de regime, autoritário ou constitucional” (PINHEIRO, 1991, p. 47).

Para termos uma ideia da permanência dessas práticas, quatro anos após a promulgação da Constituição Cidadã, ocorreria o maior massacre da história das penitenciárias brasileiras. Em outubro de 1992, as pessoas acordaram com a notícia de que uma "rebelião ocorrida na Casa de Detenção de São Paulo e a invasão do presídio pela PM deixou 111 mortos" (CHACINA..., 1992, p. 01). No dia seguinte ao acontecimento, foi estampada a imagem de cadáveres nus dos presos que haviam sido massacrados na chacina da Casa de Detenção, lado a lado, dentro de caixas de madeira enfileiradas no chão do Instituto Médico Legal (MORTOS..., 1992, p. 01). Segundo um colunista do jornal, Mário Vitor do Santos (1992), foi tamanha a carnificina que ocorreu na Casa de Detenção que a Folha de São Paulo, para diminuir a agressividade da cena, aplicou um retoque sobre a imagem.

Dois anos depois, essas arbitrariedades do aparato repressivo ocorreram nas ruas do estado do Rio de Janeiro. Em outubro de 1994, noticiava-se que 120 policiais civis haviam invadido a favela Nova Brasília, em Bonsucesso, e assassinado 13 pessoas, tipificadas como supostos traficantes. Ao ser questionado sobre o episódio, o comandante da operação reconheceu que houve uma represália, já que no final de semana anterior três policiais ficaram feridos em função de uma ação de traficantes. "Se nos derem balas, devolveremos balas", disse o delegado (POLíCIA..., 1994, p. 01).

Sete meses depois, novamente o aparato policial repetiu seu padrão de ação em bairros pauperizados. Em notícia de maio de 1995, informava-se que a polícia havia invadido a favela Nova Brasília e assassinado 14 pessoas. Nas palavras do governador Marcelo Alencar (1995/1998), a ação marcava o endurecimento da repressão ao crime em seu governo (POLíCIA DO..., 1995, p. 4). Por sua vez, o delegado que conduziu a operação declarou que poderia ter havido "excesso de violência em uma operação como essa”, contudo, "não poderia exigir 
uma conduta britânica dos policiais" (POLÍCIA DO..., 1995, p. 4). Dias depois, o mesmo jornal trazia a informação de que a polícia do Rio de Janeiro estava omitindo os laudos sobre os mortos. Em resposta, o assessor de imprensa da polícia civil disse que "quando morre um policial, ninguém procura o laudo [...] a polícia e a sociedade saíram ganhando com a ação [...] não morreu nenhum trabalhador [...] bandido morreu, acabou". Já os moradores disseram que pelo menos dez das vítimas já haviam se rendido quando foram mortas (POLíCIA INVADE..., 1995, p. 6). Não podemos esquecer que nesse período, o Governo de Marcelo Alencar, seguindo as orientações do Secretário de Segurança Pública, o Gal. da reserva Nilton Cerqueira Junior, instituiu o que ficou popularmente conhecido como "gratificação faroeste", que era o pagamento por mérito em ações que o policial agisse com "destemida coragem para alcançar o sucesso nas missões".

Um ano depois, a morte de vários trabalhadores rurais sem-terra no Pará ocupava as páginas de vários jornais do país. Uma operação da polícia militar em Eldorado dos Carajás, em abril de 1996, acabou com a morte de 19 trabalhadores rurais sem-terra e 60 feridos (CONFRONTO..., 1996, p. 8). As informações são de que 200 policiais tentaram liberar a Rodovia PA-150, interditada por mais de 3.500 trabalhadores sem-terra. As explicações do governo de Almir Gabriel (1995/2002) sobre o episódio são de que os policiais foram recebidos a tiros, versão negada pelos sem-terra (CONFRONTO..., 1996, p. 8). O médico que atendeu as vítimas verificou que "os corpos têm várias perfurações de bala, inclusive na cabeça" (CONFRONTO..., 1996, p. 8)). No dia seguinte, consta a informação de que o episódio que levou à morte os trabalhadores, tinha "indício de assassinato" (AÇÃO..., 1996, p. 4). Destaca-se também que nas imagens de tevês locais é possível observar policiais militares armados de metralhadora atirando nos semterra (AÇÃO..., 1996, p. 4).

Diante desse legado de um autoritarismo socialmente implantado, marcado por diversos tipos de ilegalidades nas ações do aparato repressivo, foram formulados pelo governo federal vários programas (1996, 2002, 2009) em defesa dos direitos humanos, com o intuito de criar uma concepção dos direitos civis e individuais considerados inalienáveis, indissociáveis e universais. 
Procurava-se construir a premissa de que a defesa dos direitos humanos pertencia a todas as pessoas, condição sine qua non para a promoção de uma democracia plena no país. Embora os programas reconhecessem a indivisibilidade dos direitos humanos, o Ministério da Justiça sinalizava a necessidade de ressaltar a realização dos direitos civis e individuais, para que a população assumisse que os direitos humanos eram direitos de todos.

Paulo Sérgio Pinheiro e Paulo de Mesquita Neto (1997, p. 117), em meados dos anos 1990, pontuaram que o massacre de Eldorado dos Carajás parecia um "mau presságio para os planos do governo Fernando Henrique Cardoso de reformar o Estado e democratizar a sociedade, consolidar o Estado de direito e ampliar as garantias dos direitos de cidadania e humanos no Brasil". Não é sem sentido que no I Programa Nacional de Direitos Humanos estava expresso que "direitos humanos são os direitos fundamentais de todas as pessoas [...] todos, enquanto pessoas, devem ser respeitados e sua integridade física protegida e assegurada" (BRASIL, 1996).

Com essa política, o governo brasileiro, pela primeira vez na história republicana, adotava e defendia os direitos humanos. Conforme Pinheiro e Mesquita Neto (1997, p. 120), quando do lançamento do primeiro programa, se transformou em "um quadro de referência para a concretização das garantias do Estado de direito e para a ação em parceria do Estado e da sociedade civil [...]", era a afirmação de uma "nova concepção de direitos humanos, [...] que não apenas estavam definidos em constituições e leis nacionais, mas também correspondiam a obrigações assumidas em tratados internacionais ratificados pelo Congresso Nacional" (PINHEIRO; MESQUITA NETO, 1997, p. 120).

$\mathrm{Na}$ realidade, o país procurava se alinhar aos principais países desenvolvidos na adoção de um constitucionalismo social e humanístico constituído após a Segunda Guerra Mundial, expresso em um dos principais tratados internacionais, a Declaração Universal dos Direitos Humanos (DUDH), promulgada em 1948, considerada um dos mais importantes acordos na defesa de direitos considerados inalienáveis do ser humano. A internalização/incorporação de alguns postulados presentes nesses documentos 
internacionais já aparece na constituição de 1988, tendo em vista que o valor da dignidade humana foi elevado a princípio fundamental.

O postulado da dignidade humana, contido na Carta de 1988, foi basilar, inclusive, para a ratificação de outros tratados internacionais de proteção dos direitos humanos, celebrados ao longo das décadas seguintes. Para os propósitos deste trabalho, destacamos a Convenção contra a Tortura e outros Tratamentos Cruéis, Desumanos e Degradantes, de 28/09/1989; Pacto Internacional dos Direitos Civis e Políticos, de 24/01/1992; Convenção Americana de Direitos Humanos, de 25/09/1992; Protocolo à Convenção Americana referente à Abolição da Pena de Morte, 13/08/1996; Estatuto de Roma, que criou o Tribunal Penal Internacional, 20/06/2002; Protocolo Facultativo à Convenção contra a Tortura, 11/01/2007; Pacto visando à Abolição da Pena de Morte, 25/09/2009.

Vale uma menção especial a Declaração e Programa de Ação de Viena, de 25/11/1993, à medida que trata da relação entre os direitos humanos e a soberania no sistema internacional. O documento ficou conhecido como o direito dos tratados, pois passou a definir claramente como os Estados deveriam manifestar seu assentimento quanto aos compromissos pactuados (DECLARAÇÃO..., 1993). É considerado como um divisor de águas, pois procurava harmonizar os procedimentos de elaboração e ratificação dos atos jurídicos internacionais. Apesar de seus princípios terem sido incorporados nos três PNDHs, só foi ratificado pelo país em 2009.

Apesar dessa internalização dos postulados dos direitos humanos na sociedade brasileira, quando do lançamento do primeiro Programa Nacional de Direitos Humanos (PNDH-1), em 1996, já se falava que os resultados seriam incertos e dependeriam muito da forma pela qual o Estado, os segmentos políticos e a sociedade civil se comprometeriam e como participariam em sua implementação. Em maio de 1996, consta a informação que o programa teria algumas resistências por parte do congresso, dentre elas a de "atribuir à justiça comum a competência para processar e julgar os crimes cometidos por policiais militares" (PLANO..., 1996, p. 4). Apesar de o colunista do jornal, Fernando Rodrigues (1996) salientar que "é difícil não aplaudir a ideia de FHC de lançar um plano nacional para defender os direitos humanos". O próprio jornal, em editorial, 
destacava a fala do presidente da república de que era necessário "estancar a banalização da morte” no país (PLANO..., 1996, p. 4).

No final de seu governo, Fernando Henrique Cardoso voltou a lançar um novo programa nacional de direitos humanos, contendo 518 propostas, para dar continuidade ao anterior, de 1996. No lançamento, em 13 de maio de 2002, uma data simbólica, o presidente da República fazia questão de frisar que as "as ações anunciadas constituem verdadeiras políticas de Estado e não apenas atos desse governo" (SÓ 30\%..., 2002, p. C1). Nesse caso, pedia ao novo governante que não limitasse suas ações na área dos direitos humanos, pois entendia que havia "respaldo da sociedade brasileira e não podia se esgotar em um mandato presidencial” (PARA..., 2002, p. 4).

Para os propósitos deste trabalho, destacamos que dentre as 518 propostas contidas no PNDH-2, propunha-se incluir no currículo dos cursos de formação de policiais módulos específicos sobre direitos humanos, técnica não letais de intervenção policial e mediação de conflitos, apoiar programas para a redução da letalidade em ações envolvendo policiais e modernizar as corregedorias independentes e desvinculadas dos comandos policiais, com vistas a limitar os abusos e erros em operações policiais (BRASIL, 2002).

Em continuidade a essa política de implantação de uma política de direitos humanos no país, o Governo Lula lançou o PNDH-3 no final de 2009. Como podemos perceber, essa temática entrara definitivamente na agenda política do país, passando a ser entendida como uma política de Estado e não de um governo. O programa lançado pelo governo petista manteve os postulados contidos nos programas (1996 e 2002) de Fernando Henrique Cardoso, acrescentando outros, demonstrando, com isso, certa continuidade na afirmação de alguns princípios presentes na Constituição de 1988, denominada constituição cidadã.

O PNDH-3, lançado em 21 de dezembro de 2009, mantinha as propostas do plano anterior e trazia algumas novidades. Para os objetivos deste trabalho, que diz respeito à repressão e à violência estatal, o plano apontava para a necessidade de reforma do modelo de polícia, com ênfase na erradicação da tortura, na redução da letalidade policial e de combate às execuções 
extrajudiciais realizadas por agentes do Estado, assegurando a investigação dessas violações; propunha estimular a discussão sobre modelos alternativos de tratamento de uso e tráfico de drogas, criar ouvidorias de polícia independentes para exercer o controle externo das atividades policiais e consolidar uma política nacional visando à erradicação da tortura e de outros tratamentos ou penas cruéis, desumanos ou degradantes (BRASIL, 2009).

Podemos claramente observar que o PNDH-3, promulgado pelo Governo Lula, dava continuidade aos planos anteriores e acrescentava outras ações, mas sempre seguindo uma política visando consolidar o ideário dos direitos humanos e o fortalecimento da democracia no país. Para Sérgio Adorno (2010, p. 05), "comparado às edições anteriores, o PNDH-3 situa-se na linha evolutiva das ideias e dos programas governamentais".

Chama a atenção no PNDH-3 que não houve qualquer cobertura imediata por parte da imprensa. Se nos planos anteriores logo foi aberto um espaço para divulgar o teor do documento, os avanços e os pontos polêmicos, no lançado pelo governo petista houve um silenciamento. A impressão é de que o plano apresentado pelo presidente Lula, em 21 de dezembro de 2009, não era digno de atenção, de algo que merecia ser noticiado. Com efeito, a imprensa começou a dar alguma visibilidade ao conteúdo do PNDH-3 quando apareceram as primeiras críticas. A Folha de São Paulo, por exemplo, apenas começou a fazer matérias no início de 2010, para dar destaque de que segmentos da sociedade civil estavam criticando o Plano Nacional de Direitos Humanos do governo Lula e que membros do próprio governo se posicionaram contrariamente ao decreto presidencial (SETOR..., 2010, p. A6; MINISTRO..., 2010, p. 1). Blogueiro de uma revista semanal chegou a dizer que o Presidente Lula "assinou um decreto que tem fedor de um golpe de estado branco" (AZEVEDO, 2010).

Com efeito, os direitos humanos passaram, portanto, a partir do PNDH-3 promulgado no final de 2009, a serem vistos como uma ameaça à sociedade brasileira e não um aprofundamento do nosso regime democrático. Verifica-se claramente uma crítica generalizada de vários segmentos da sociedade civil e de políticos, demonstrando, com isso, inúmeros limites para se continuar no processo de implementação desse ideário na sociedade brasileira. Todavia, 
necessário entender que essas dificuldades foram se constituindo pari passu à democratização do país, porém, a partir da última década, houve uma inflexão significativa em torno do tema dos direitos humanos. É necessário, assim, acompanharmos esse processo histórico.

\section{c) Chocando o ovo da serpente}

Romper com um padrão sócio-político de desrespeito aos direitos humanos - repressão, violência e arbitrariedades -, enraizado na trajetória histórica da sociedade brasileira não seria nada fácil. As primeiras dificuldades começaram a aparecer ao longo da década de 1980, período no qual o país caminhava em sua transição para a democracia. A bandeira dos direitos humanos, que fora muito utilizada pelos grupos políticos para denunciar as arbitrariedades do regime militar, não teve a mesma aceitação para a defesa de direitos de pessoas pertencentes aos segmentos populares que sofriam algum tipo de violência por parte de agentes do Estado. A empatia que foi gerada em relação aos perseguidos pela ditadura militar não se repetiu em relação a segmentos pauperizados que eram vítimas da violência do Estado.

Em pesquisa realizada por Tereza Pires do Rio Caldeira (1991), relativa aos direitos humanos, é possível notar que no processo de transição para a democracia essa concepção foi mudando de conotação. Começaram a aparecer vozes contrárias de que os direitos humanos poderiam ser usados como referência para defender os direitos de pessoas pertencentes aos segmentos populares e incriminadas pelo aparato repressivo-judicial, principalmente prisioneiros comuns. Usar o princípio dos direitos humanos para defender as pessoas acusadas ou mesmo indiciadas no Brasil democrático passou a ser visto como negativo, como se estivesse protegendo um bandido, um criminoso. No dizer de Tereza Pires do Rio Caldeira:

De reivindicação democrática central no processo da chamada abertura política, defendida por amplos setores da sociedade, os direitos humanos foram transformados, no contexto de discussões sobre a criminalidade, em "privilégios de bandidos" a serem combatidos pelos homens de bem. (CALDEIRA, 1991, p. 162) 
Caldeira (1991) acrescenta que esses segmentos insistiam que criar qualquer forma de controle da violência praticada pelo aparato estatal era limitar o trabalho policial. Políticos conservadores, estrategicamente, enfatizaram que a criminalidade estava associada ao regime democrático, ou seja, que governos que adotavam políticas em defesa de direitos humanos estavam sendo lenientes com os bandidos. Inclusive, defendiam a permanências das estruturas repressivas constituídas durante os governos militares.

De forma concomitante, cresceu consideravelmente o ideário político de que havia um grave problema de segurança pública e a maneira de resolver deveria se dar por intermédio do aparato repressivo-judicial. O resultado, para usarmos as palavras de Loïc Wacquant (2011), foi de se criar uma verdadeira ditadura sobre os pobres. É devido a isso que o sociólogo francês, grande estudioso das políticas penais na contemporaneidade, assevera, que apesar da ditadura militar no Brasil ter acabado no plano político, o autoritarismo ainda prevalece e pode ser percebido nas ações repressivas da polícia em bairros populares.

Assim sendo, as práticas do aparato repressivo foram norteadas, em grande medida, pela nova racionalidade punitiva gestada nos países centrais do capitalismo. Para muitos políticos e apresentadores de programas televisivos e radiofônicos, isso apareceu como o canto da sereia. Tal como nos Estados Unidos e Europa, no Brasil também nos deparamos com uma mídia que passou a construir verdadeiras cruzadas para legitimar uma intervenção institucional cada vez mais repressiva e violenta (BATISTA, 2002). Como sinaliza Nilo Batista, "o discurso criminológico midiático pretendeu se constituir em instrumento de análise dos conflitos sociais e das instituições públicas.” (BATISTA, 2002, p. 276).

Em decorrência disso, tivemos nesses últimos trinta anos de vivência de um país democrático, um aumento vertiginoso do aprisionamento, seguindo a nova racionalidade punitiva. Se, em 1990, tínhamos em torno de 90 mil pessoas encarceradas, em 2018 atingimos a marca de 812 mil, aumento de mais de 800\%, conforme dados fornecidos pelo Conselho Nacional de Justiça nesse período. É mister assinalar que da população carcerária, 41,5\% são presos provisórios. Com 
esse número de aprisionados ficamos atrás somente da China (1,6 milhão) e dos EUA (2,3 milhões) em população carcerária (POPULAÇÃO..., 2018; CNJ..., 2019).

As cruzadas para legitimar uma intervenção estatal não se limitaram a uma política de segurança pública mais repressiva, que levou ao aumento exponencial do encarceramento no país, pois alguns segmentos sociais e políticos passaram a defender também o uso da força letal de forma legal e até mesmo ilegal. Essa política de segurança pública provocou um aumento da intolerância do aparato estatal; por consequência, tornou-se uma constante na vida de moradores de bairros populares e favelas, os abusos policiais e a intensificação da repressão. Não é sem sentido que as notícias sobre a existência de vários Esquadrões da Morte do país continuaram ocupando espaço nesse período do Brasil democrático. Em matéria de 26 de outubro de 2003, a Folha de São Paulo fez uma reportagem sobre a existência desses grupos em vários estados, que atuavam com a participação de policiais (QUADRILHAS..., 2003, p. C1). Demonstrou-se, com isso, que os Esquadrões da Morte não foram controlados ou extintos, mesmo o país vivendo sob a vigência de um Estado de direito. Portanto, os "homens de ouro", que atuavam nos Esquadrões da Morte nos anos 1960/70, continuaram a fazer parte da realidade do país (GRUPO..., 2003, p. 1).

Nesse mesmo ano de 2003, o Centro de Justiça Global produziu um relatório acerca das execuções sumárias no país. Uma das conclusões foi de que os grupos de extermínio nasciam como estratégia de comerciantes, empresários e outros segmentos da sociedade para abolir grupos políticos ou sociais indesejados (CENTRO DE JUSTIÇA GLOBAL, 2003). Portanto, uma cultura arraigada na sociedade brasileira, que usava o grupo de extermínio para promover a chamada "limpeza social", continuava ainda presente em muitas cidades do país. Os argumentos utilizados por esses grupos eram a falência das instituições para combater o crime, pois na lógica dos justiceiros, como o Estado não garantia a segurança dos cidadãos, cabia a eles limpar a comunidade da escória que matava e roubava. No relatório, consta ainda a informação que o perfil das vítimas era um conjunto de pessoas pobres, adultos e crianças, suspeitos de ilícitos ou mesmo indivíduos considerados indesejáveis (CENTRO DE JUSTIÇA GLOBAL, 2003). 
Interessante que os acusados de fazerem parte, dar suporte ou apoio aos grupos de extermínio acabavam, muitas vezes, negando esse comportamento, não assumiam publicamente o envolvimento nessas ações ilegais. Entretanto, em 2003, o atual presidente da república, um ex-militar, em discurso na Câmara Federal, afirmou que apoiava os grupos de extermínios que agiam em diversos estados do nordeste, principalmente na Bahia. Segundo o então deputado, "enquanto o Estado não tiver coragem de adotar a pena de morte, o crime de extermínio, no meu entender, será muito bem-vindo. Se não houver espaço para eles na Bahia, podem vir para o Rio de Janeiro" (BOLSONARO, 2003). Na mesma sessão, aproveitou para atacar a política de direitos humanos ao bradar de forma inflamada que "desde que a política de direitos humanos chegou ao país, a violência só aumentou e passou a ocupar grandes espaços nos jornais. A marginalidade tem estado cada vez mais à vontade, tendo em vista os neoadvogados para defendê-la." (BOLSONARO, 2003).

Não é nosso propósito discutir a pauta dos costumes, mas da repressão e ilegalidades contra os segmentos sociais mais vulneráveis, contudo, uma declaração do então deputado Jair Bolsonaro não poderia deixar de ser mencionada, pois tem uma relação direta com essa questão. No que tange à união civil entre pessoas do mesmo sexo, proferiu que não iria "combater nem discriminar, mas se eu vir dois homens se beijando na rua, vou bater" (SUWWAN, 2002). Como podemos verificar, um parlamentar, que já começava a ocupar grande espaço na mídia e ser porta-voz dos segmentos de direita no país, defendia claramente que homossexuais deveriam ser agredidos, legitimando, assim, violências e arbitrariedades contra esse grupo social.

Em continuidade ao ideário em defesa do uso da violência legal e ilegal por parte do aparato estatal que começava a ganhar cada vez mais visibilidade, cinco anos depois do deputado Federal Jair Bolsonaro defender os grupos de extermínio e alardear que eram bem-vindos ao Rio de Janeiro, o deputado estadual Flávio Bolsonaro, seu filho, assumiu a Comissão de Direitos Humanos da Assembleia Legislativa do Rio de Janeiro, em 2007, com a intenção de legalizar as milícias e de defender o uso de carros blindados em operações policiais nas favelas. Ao ser questionado que suas posições eram contrárias aos princípios 
contidos na Declaração Universal de Direitos Humanos, justificou: "para mim, direitos humanos não são para todos os humanos, porque algumas pessoas não podem nem ser chamadas de seres humanos" (DEPUTADO..., 2007). A matéria traz ainda a informação que o referido parlamentar tinha sido visto várias vezes, na Alerj, usando uma camiseta com os dizeres "direitos humanos, a excrescência da vagabundagem". Sobre as milícias, Bolsonaro falava que tinha conhecimento de que elas cobravam tarifas, mas que conhecia algumas comunidades em que os trabalhadores faziam questão de pagar $\mathrm{R} \$ 15$ para não terem traficantes. Alega que, muitas vezes, sente-se um pouco estigmatizado, mas admite que não é refém da ditadura do politicamente correto (DEPUTADO..., 2007).

Nesse mesmo ano em que o deputado Flávio Bolsonaro, atualmente senador da república, declarava que tinha intenção de legalizar as milícias, um relatório da Human Rights Watch (2007) apontava que um dos maiores problemas do país, no tocante aos direitos humanos, era justamente a violência policial, pois esses agentes se envolviam em práticas abusivas e ilegais em ações nos bairros populares e comunidades. No caso do Rio de Janeiro, o relatório assinalava o aumento significativo das milícias ligadas ao aparato policial. Se, no parlamento do Estado, o deputado procurava convencer os demais sobre a importância das milícias para resolver o problema dos crimes no país, o relatório da Human Rights Watch salientava que no primeiro semestre de 2007, a polícia assassinara 694 pessoas em situações descritas como "resistência seguida de morte", um terço a mais do que ano anterior. Em muitas operações, as pessoas foram mortas em alegados confrontos com a polícia (HUMAN RIGHTS WATCH, 2007).

Em um movimento concatenado de apoio aos milicianos no ano de 2008, o deputado federal Jair Bolsonaro aproveita uma sessão da Câmara Federal para tecer duras críticas a uma CPI ocorrida na Assembleia Legislativa do Rio de Janeiro sobre a atuação dos grupos armados no Estado. Nas palavras do parlamentar, os "deputados do seu estado não faziam nada para diminuir o poder dos traficantes, mas atacavam os milicianos, alegando que eram 'símbolos da maldade e pior do que os traficantes"' (BOLSONARO, 2008). Argumenta que eles não entendem que muitas vezes esse grupo social que está sendo acusado usa 
a sua própria arma para organizar a segurança da sua comunidade. E termina seu discurso avaliando que é um "relatório covarde, feito em cima do disquedenúncia” (BOLSONARO, 2008).

Se o governo Lula lançou o PNDH-3 no final de 2009 em um clima festivo de final de ano, como noticiou a imprensa, ao longo do ano de 2010 veremos cada vez mais os jornais noticiarem o aumento da violência legal e ilegal do aparato policial, especialmente em função do poder que as milícias possuíam em várias comunidades no estado do Rio de Janeiro, mas também em inúmeras cidades espalhadas pelo país (TESTEMUNHAS..., 2010). O relatório da Human Rights Watch, de 2009, trazia a informação de que no Rio de Janeiro, milícias ligadas a policiais controlavam dezenas de comunidades sob mira de armas, extorquindo moradores e cometendo homicídios e outros crimes violentos. Relatório da Alerj apontava que 171 comunidades no estado eram "dominadas" por milícias (HUMAN RIGHTS WATCH, 2009). Por sua vez, a cidade de São Paulo foi mencionada no relatório da Anistia Internacional justamente em função das chacinas, cujos responsáveis estariam ligados a grupos policiais de extermínio e a grupos criminosos (ANISTIA INTERNACIONAL, 2011).

Se tratamos do avanço das milícias no Rio de Janeiro, temos que destacar que o PNDH-3, lançado pelo presidente Lula no final de 2009, sofreria duros ataques ao longo de todo o ano de 2010. Não nos estenderemos nesse ponto, mas frisamos que ao longo de 2010, vários jornais davam ênfase ao descontentamento de segmentos da sociedade brasileira em relação ao PNDH3. Venício Lima (2010), no site Observatório da Imprensa, escreveu que "desde sua publicação no final de dezembro de 2009, o PNDH-3 passou a ser "objeto de violenta campanha conservadora apoiada e, em parte, promovida pela grande mídia”. Na realidade, matérias veiculadas pela imprensa frisavam que o PNDH-3 era inspiração de guerrilheiros pretéritos (MARTINS, 2010). Em outra matéria, há a informação que a bancada evangélica, que crescera de 56 para 68 congressistas, tinha como uma das metas trabalhar pela extinção do PNDH-3 enviado ao legislativo pelo governo (BANCADA..., 2010, p. A17).

Depreendemos das inúmeras matérias da grande imprensa, na última década, que o entendimento majoritário era de que o novo plano nacional de 
direitos humanos era uma afronta à democracia, ao estado de direito, com claras intenções de instituir um Estado autoritário ou totalitário, um projeto socialista da esquerda que pretendia fazer do Brasil uma nação presa em teias comunistas que caminhava para o caos familiar, social, político e econômico, que distorcia conceito e invertia valores, proporcionava privilégios escusos para baderneiros e "camaradas" e perseguia a virtude e o mérito.

Nos anos seguintes da divulgação do PNDH-3, ganhou cada vez mais força o ideário que era necessário reverter a implantação da política de direitos humanos idealizada pelos planos elaborados nos governos FHC e Lula. Com efeito, as denominadas bancadas evangélica, ruralista e "da bala" passaram a se articular para justamente alterar o teor do PNDH-3; intencionavam montar um novo plano alinhado com suas concepções sobre o preconceito, a violência policial, direitos de negros e mulheres, além do tema LGBT (AÉCIO..., 2014).

A Agência Brasil, em 09 de outubro de 2014, destacava que "algumas conquistas do processo civilizatório, como a garantia dos direitos humanos, podem ser interrompidas ou mesmo regredir com a eleição de uma bancada conservadora" (MAIS..., 2014). Um analista político do DIAP declarava que seria o congresso mais conservador desde a redemocratização. Na matéria, enfatizava que deputados como Moroni Torgan, do Ceará, Alberto Fraga, do Distrito Federal e Jair Bolsonaro, do Rio de Janeiro, defendiam a revisão do Estatuto do Desarmamento, a redução da maioridade penal e a criação de leis mais rígidas para punir crimes. Por outro lado, os deputados identificados com a defesa dos direitos humanos não foram reeleitos (MAIS..., 2014).

Em continuidade a esse avanço conservador e de questionamentos orquestrados, o candidato que sempre teve uma posição diametralmente oposta ao ideário dos direitos vai se apresentar como candidato à presidente da república em 2018, e defender como proposta a reversão dessa política que fora implantada pelos governos anteriores. Podemos inferir que as propostas do candidato a presidente da República, Jair Bolsonaro, tinham o intuito de intensificar a repressão, ter maior rigor nas punições, flexibilizar os usos de armas e garantir que policiais não fossem punidos caso usassem a força letal nas operações repressivas. 
Assim sendo, a candidatura de Bolsonaro dava materialidade a algumas ideias que vinham sendo gestadas, particularmente na virada do século para cá. Não é sem sentido que quando assumiu o cargo de presidente da república, indicou o ex-juiz Sérgio Moro para o Ministério da Justiça e Segurança, para justamente implantar as propostas que defendera durante a campanha. Para colocar isso em prática, no dia 04/02/2019, o ex-juiz apresentou um pacote de medidas com vistas a enfrentar os grandes problemas da segurança pública vivenciados pelos cidadãos (ENTENDA..., 2019). Basicamente, seu projeto “anticrime" tinha como pressuposto uma concepção punitivista na resolução dos problemas sociais, a intensificação das ações repressivas e a legitimação do uso da força letal por parte dos agentes do Estado.

Portanto, a partir do governo Bolsonaro, a tendência era de que o Ministério da Justiça e Segurança seguisse o pressuposto de "entupir a cadeia de bandidos", logicamente oriundos de parcelas da população desprovidas de proteção social. Isso acaba por provocar ainda mais problemas ao sistema prisional brasileiro e da segurança de uma forma geral, pois o número de encarcerados continuará com uma tendência de alta, contribuindo de forma significativa com o recrutamento de jovens pelas organizações criminosas que dominam os presídios do país.

O excludente de ilicitude, contido nas propostas anticrime, vai agravar ainda mais a violência policial, já considerada um dos graves problemas a serem enfrentados no país. Com efeito, o uso indiscriminado da força policial e a institucionalização da morte como método legitimado e normalizado de combate ao crime são concebidos como política de segurança pública. Para se ter uma ideia da legitimação dessa violência legal e ilegal, o presidente da república declarou que tem intenção de conceder indultos aos policiais envolvidos nas ações ilegais de Eldorado dos Carajás, Massacre do Carandiru e do sequestro do Ônibus 174 (BOLSONARO..., 2019).

Com autorização para o uso da força letal nas ações repressivas, a tendência é que haverá um recrudescimento da violência legal e ilegal por partes dos agentes do Estado, colocando em risco a integridade física de muitas pessoas que vivem em bairros periféricos ou comunidades. Para 
exemplificarmos, jornais noticiam que o número de mortes provocadas por policiais bate recordes no primeiro ano do governo Bolsonaro. Segundo dados do Instituto de Segurança Pública do Estado do Rio de Janeiro, 1.249 casos foram registrados de janeiro a agosto de 2019 (AUMENTO..., 2019). As explicações do governador do estado, Wilson Witzel, para esse aumento significativo do número de pessoas mortas é que os "bandidos" "serão caçados nas comunidades e aqueles que não se entregarem, não tirarem o fuzil do tiracolo serão abatidos" (NO RIO..., 2019).

No que diz respeito à introdução do acordo (plea bargain) entre o réu e o ministério público, copiado do modelo americano, os impactos devem ser catastróficos, tanto no que tange ao sistema prisional quanto em relação às garantias constitucionais, especialmente daqueles que não podem contar com serviços jurídicos. Aquele que for acusado, incriminado, por exemplo, pode se declarar culpado com receio de um julgamento negativo, logo, passará a cumprir a pena imediatamente, contribuindo ainda mais no aumento dos encarcerados.

Na possibilidade do acordo (plea bargain), há também uma situação de vulnerabilidade e de assimetria entre o réu e o Ministério Público, em um cenário com procuradores poderosos, flexibilidade de garantias constitucionais e desconsideração de padrões probatórios mínimos (STRECK, 2019). Essa situação pode ser agravada ainda mais em se tratando de pessoas pobres que não têm recursos para contratar advogados e dependem das defensorias públicas, insuficientes na maioria dos estados.

Para concluir, assinalamos que nessa trajetória histórica do Brasil democrático, houve avanços importantes na efetivação de um estado democrático de direito, com respeito às liberdades individuais e coletivas, com a adoção por diferentes governos de uma política de direitos humanos como se fosse uma política de Estado. Todavia, de forma concomitante, foi crescendo um ideário de direita e extrema-direita que passou a se posicionar de forma diametralmente oposta à política de direitos humanos. Se no início do processo de democratização não teve força suficiente, pois colocava somente alguns obstáculos, na implantação dos direitos humanos no país, na última década vem, de forma concatenada, revertendo as conquistas que haviam sido obtidas. 
Esses segmentos sociais que lideram esse movimento querem, inclusive, alterar o teor dos sucessivos planos e constituir uma nova compreensão acerca de direitos humanos. Alguns chegam a falar que direitos humanos são para humanos direitos. Portanto, o ovo da serpente foi sendo chocado e como resultado, na atualidade, temos um governo que pretende institucionalizar um Estado mínimo na proteção social e um Estado máximo no encarceramento e na repressão legal e ilegal, além de fragilizar as garantias jurídicas e processuais de pessoas alvos do aparato estatal. Desse modo, ao se colocar em xeque o ideário dos direitos humanos na atualidade, estamos nos deparando com retrocessos significativos nas conquistas obtidas desde a redemocratização do país. Quando finalizava este artigo, os principais jornais do país traziam a notícia de que o governo Bolsonaro excluiu os indicadores de violência policial praticada no Brasil, no ano de 2019, do relatório sobre direitos humanos.

Espero que essa tendência seja freada pelas forças democráticas deste país.

\section{Referências}

AÇÃO da polícia no pará tem indício de assassinato. Folha de São Paulo, São Paulo, ano 76, n. 24.488, p. 04, 19 abr. 1996. Disponível em https://acervo.folha.com.br/index.do. Acesso em: 26 set. 2019.

ADORNO, Sérgio. História e desventura: o 3o Programa Nacional dos Direitos Humanos. Novos Estudos, São Paulo, n. 86, p. 5-20, mar. 2010.

AÉClO quer rever Plano de Direitos Humanos com congresso de perfil conservador. Rede Brasil Atual, São Paulo, 21 out. 2014. Disponível em: https://www.redebrasilatual.com.br/cidadania/2014/10/aecio-escondeproposta-pro-lgbt-e-de-revisao-de-programa-de-direitos-humanos-9201/. Acesso em: 30 ago. 2019. 
ANISTIA INTERNACIONAL. Informe 2011. Londres: Anistia Internacional, 2011. p. 114. Disponível em: https://anistia.org.br/wp-content/uploads/2014/08/Informeanual-2011.pdf. Acesso em: 05 nov. 2019.

Aumento da letalidade policial não diminui crimes, diz estudo do MP-RJ. Consultor Jurídico, São Paulo, 29 set. 2019. Disponível em: https://www.conjur.com.br/2019-set-29/aumento-letalidade-policial-naodiminui-crimes-mp-rj. Acesso em: 27 jul. 2019.

AZEVEDO, Reinaldo. O suposto decreto dos direitos humanos prega um golpe na justiça e extingue a propriedade privada no campo e nas cidades. Está no texto. Basta ler!!!. Portal Veja. São Paulo, 07 jan. 2010. Disponível em: https://veja.abril.com.br/blog/reinaldo/o-suposto-decreto-dos-direitoshumanos-prega-um-golpe-na-justica-e-extingue-a-propriedade-privada-nocampo-e-nas-cidades-esta-no-texto-basta-ler/. Acesso em: 10 out. 2019.

BANCADA evangélica quer barrar o plano de direitos humanos. Folha de São Paulo, São Paulo, ano 90, n. 29.774, p. A17, 09 out. 2010. Disponível em: https://acervo.folha.com.br/index.do. Acesso em: 27 jul. 2020.

BARDIN, Laurence. Análise de conteúdo. São Paulo: Edições 70, 2011.

BATISTA, Nilo. Mídia e sistema penal no capitalismo tardio. Discursos sediciosos: crime, direito e sociedade, Rio de Janeiro, Ano 7, n. 12, p. 271-288, 2. sem. 2002.

BOBBIO, Norberto. A era dos direitos. Rio de Janeiro: Elsevier, 2004.

BOLSONARO, Jair Messias. Críticas ao relatório final da CPI das milícias, realizada pela Assembleia Legislativa do Estado do Rio de Janeiro. Brasília: Câmara dos Deputados, 2008. Discursos e notas taquigráficas. Disponível em: https://www.camara.leg.br/internet/sitaqweb/TextoHTML.asp?etapa=5\&nuSessa $\mathrm{o}=326.2 .53 .0+++++\&$ nuQuarto $=20 \&$ nuOrador $=1 \&$ nulnsercao $=0 \& d$ thorario Quarto $=$ 15\%3A48\&sgFaseSessao=BC++++++++\&Data=17\%2F12\%2F2008\&txApelido=JAIR + BOLSONARO\&fbclid=IWAROo_uiqvWnZ1UL8PwHp8WTiBYXEZRZam7JMBJX_D5Y0o n6ouNqVvZtACH8. Acesso em: 20 ago. 2019.

BOLSONARO, Jair Messias. Reflexos das ações de grupos de extermínio na queda do índice de violência e de criminalidade no Estado da Bahia. Brasília: Câmara dos Deputados: 2003. Discursos e notas taquigráficas. Disponível em: https://www.camara.leg.br/internet/sitaqweb/TextoHTML.asp?etapa=5+++++++ $+++++++++++++++++++++\&$ nuSessao $=138.1 .52 .0++++++++++++++++++++++++$ $+++++++++\&$ nuQuarto $=13++++++++++++++++++++++++++++\&$ nuOrador $=1++++$ $++++++++++++++++++++++++\&$ nulnsercaO $0+++++++++++++++++++++++++++$ $+\&$ dtHorarioQuarto $=14: 54++++++++++++++++++++++++++++\&$ sgFase Sessao $=\mathrm{BC}$ ++++++++++++++++++++++++++++++++++++\&Data $12 / 08 / 2003++++++++++++$ ++++++++++++++++ \&tXApelido=JAIR+BOLSONARO. Acesso em: 20 ago. 2019. 
BOLSONARO DARÁ indulto a policiais de Eldorado dos Carajás, Carandiru e ônibus 174. Portal Uol Notícias, São Paulo, 31 ago. 2019. Disponível em:

https://noticias.uol.com.br/ultimas-noticias/agenciaestado/2019/08/31/bolsonaro-dara-indulto-a-policias-de-eldorado-dos-carajascarandiru-e-onibus-174.htm. Acesso em: 02 set. 2019.

BRASIL. [Constituição (1988)]. Constituição da República Federativa do Brasil de 1988. Brasília, DF: Presidência da República. Disponível em:

http://www.planalto.gov.br/ccivil_03/constituicao/constituicao.htm. Acesso em: 27 jul. 2019

BRASIL. Decreto $n^{\circ}$ 1.904, de 13 de maio de 1996. Aprova I Programa Nacional de Direitos Humanos. Brasília: Câmara dos Deputados, 1996. Disponível em: https://www2.camara.leg.br/legin/fed/decret/1996/decreto-1904-13-maio-1996431671-publicacaooriginal-1-pe.html. Acesso em: 18 out. 2019.

BRASIL. Decreto no 4.229, de 13 de maio de 2002. Dispõe sobre o Programa Nacional de Direitos Humanos - PNDH, instituído pelo Decreto no 1.904, de 13 de maio de 1996 e dá outras providências. Brasília: Presidência da República, 2002. Disponível em: https://normas.gov.br/materia/-

/asset_publisher/NebW5rLVWyej/content/id/66855139. Acesso em: 18 out. 2019.

BRASIL. Decreto № 7.037, de 21 de dezembro de 2009. Aprova o programa nacional de direitos humanos pndh-3 e dá outras providências. Brasília: Presidência da República, 2009. Disponível em: http://www.planalto.gov.br/ccivil_03/_ato2007-2010/2009/decreto/d7037.htm. Acesso em: 18 out. 2019

CALDEIRA, Tereza Pires do Rio. Direitos humanos ou "privilégios de bandidos"? desventuras da democratização brasileira. Novos Estudos Cebrap, São Paulo, n. 30, p. 162-174, jul. 1991.

CAPELATO, Maria Helena e PRADO, Maria Lígia. O bravo matutino: imprensa e ideologia: o jornal O Estado de São Paulo. São Paulo: Alfa-Omega, 1980.

CARVALHO, José Murilo. Cidadania no Brasil: o longo caminho. Rio de Janeiro: Civilização Brasileira, 2005.

CENTRO DE JUSTIÇA GLOBAL. Relatório Execuções Sumárias no Brasil 1997/2003. Setembro de 2003. p. 69. Disponível em: http://www.ovpsp.org/relatorio_just_global_exec_97_03.pdf. Acesso em: 12 out. 2019.

CHACINA mata 111 presos em São Paulo. Folha de São Paulo, São Paulo. ano 72, n. 23.195, p. 01.04 out. 1992. Disponivel em:

https://acervo.folha.com.br/index.do. Acesso em: 17 jun. 2019. 
CHAVEAU, Agnès; TÉTART, Philippe. Questões para a história do presente. Bauru: Edusc, 1999.

CHRISTIE, Nils. Industria del control del delito: ¿la nueva forma del holocausto? Buenos Aires: Ediores Del Puerto, 1993.

CNJ REGISTRA pelo menos 812 mil presos no país; 41,5\% não têm condenação. Portal G1, Rio de Janeiro, 17 jul. 2019. Disponível em:

https:/g1.globo.com/politica/noticia/2019/07/17/cnj-registra-pelo-menos-812mil-presos-no-pais-415percent-nao-tem-condenacao.ghtml. Acesso em: 12 out. 2019.

CONFRONTO mata pelos menos 19 no Pará. Folha de São Paulo, São Paulo, ano 76, n. 24.487, p. 08, 18 abr. 1996. Disponível em:

https://acervo.folha.com.br/index.do. Acesso em: 26 set. 2019.

DECLARAÇÃO e Programa de Ação de Viena - 1993. São Paulo: Universidade de São Paulo: Biblioteca Virtual de Direitos Humanos, 1993. Disponível em: http://www.direitoshumanos.usp.br/index.php/Sistema-Global.Declara\%C3\%A7\%C3\%B5es-e-Tratados-Internacionais-deProte\%C3\%A7\%C3\%A3o/declaracao-e-programa-de-acao-de-viena.html. Acesso em: 27 jul. 2020.

DE GIORGI, Alessandro. Tolerancia cero: estrategias y prácticas de la sociedad de control. Barcelona: Virus, 2005.

DEPUTADO quer legalizar milícias no Rio. Portal Terra, São Paulo, 16 mar. 2007. Disponível em: https://www.terra.com.br/noticias/brasil/politica/deputadoquer-legalizar-milicias-norio,f2fe24d51491139f856ce9e94d4a88bc1m7unakr.html. Acesso em: 12 out. 2019

ENTENDA ponto a ponto as mudanças previstas pelo pacote anticrime de Moro. Folha de São Paulo, São Paulo, 04 fev. 2019, Disponível em: https://www1.folha.uol.com.br/poder/2019/02/entenda-os-principais-pontosdo-pacote-anticrime-de-moro.shtml. Acesso em: 27 out. 2020

É PRECISO haver controle das fronteiras, diz dinamarquês. Folha de São Paulo, São Paulo, ano 91, n. 29.991, p. 01, 14 maio 2011. Disponível em: https://acervo.folha.com.br/index.do. Acesso em: 11 set. 2019.

FERRAJOLI, Luigi. Derechos y garantias: la ley del mais débil. 7. ed. Barcelona: Editorial Trotta, 2010.

GARLAND, David. A cultura do controle: crime e ordem social na sociedade contemporânea. Rio de Janeiro: Revan, 2008. 
GRUPO de extermínio se alia a crime organizado. Folha de São Paulo, São Paulo, ano 83, n. 27.234, p. 01, 23 maio 2003. Disponível em:

https://acervo.folha.com.br/index.do. Acesso em: 27 set. 2019.

HAYEK, Friedrich. O caminho da servidão. São Paulo: Instituto Ludwig von Mises Brasil, 2010.

HOBSBAWM, Eric. Era dos extremos: o breve século XX - 1914-1991. 2 ed. São Paulo: Cia das Letras, 2012.

HUMAN RIGHTS WATCH. Acontecimentos de 2009. [New York: HRW], 2009. Disponível em: https://www.hrw.org/pt/world-report/2010/countrychapters/259144. Acesso em: 20 jul. 2019.

HUMAN RIGHTS WATCH. Brasil, evento de 2007. [New York: HRW], 2007. Disponível em:

https://www.hrw.org/legacy/portuguese/docs/2008/01/31/brazil17926.htm. Acesso em: 16 out. 2019

HUMAN RIGHTS WATCH. Informe mundial 2019: Estados Unidos: eventos de 2018. [New York: HRW], 2019a. Disponível em: https://www.hrw.org/pt/worldreport/2019/country-chapters/326095. Acesso em: 01 out. 2019.

HUMAN RIGHTS WATCH. Informe mundial 2019: Unión Europea: eventos de 2018. [New York: HRW], 2019b. Disponível em: https://www.hrw.org/es/worldreport/2019/country-chapters/325723. Acesso em: 01 out. 2019

HUMAN WATCH RIGHTS. Informe anual, 2005: Estados Unidos. [New York: HRW], 2005a. Disponível em:

https://www.hrw.org/legacy/spanish/inf_anual/2005/estados_unidos.html\#estad os. Acesso em: 11 set. 2019

HUMAN WATCH RIGHTS. Informe Anual, 2005: la Unión Europea. [New York: HRW], 2005b. Disponível em:

https://www.hrw.org/legacy/spanish/docs/2005/01/13/eu9973.htm. Acesso em: 11 set. 2019

HUNT, Lynn. La invención de los derechos humanos. Barcelona: Tusquets editores, 2009.

JUDT, Tony. Um tratado sobre os nossos actuais descontentamentos. Lisboa: Edições 70, 2015. 
LIMA, Venício A. Excrescências do direito à comunicação. Observatório da Imprensa, 23/10/2010. Disponível em:

http://www.observatoriodaimprensa.com.br/jornal-de-debates/excrescenciasdo-direito-a-comunicacao/. Acesso em: 27 jul. 2020

MAIS CONSERVADOR, Congresso eleito pode limitar avanços dos direitos humanos. Agência Brasil, Brasília, 09 out. 2014. Disponível em: https://agenciabrasil.ebc.com.br/politica/noticia/2014-10/mais-conservadorcongresso-eleito-pode-limitar-avancos-em-direitos-humanos. Acesso em: 27 jul. 2020.

MARSHALL, Theodor H. Política social. Rio de Janeiro: Zahar Editores, 1967.

MARTINS, Ives Gandra da Silva. Guerrilha e redemocratização. Folha de São Paulo, São Paulo, ano 89, n. 29.514, 22 jan. 2010, Disponível em: https://acervo.folha.com.br/index.do. Acesso em: 27 jul. 2020.

MINISTRO critica plano de direitos humanos. Folha de São Paulo, São Paulo, ano 90, n. 29.501, p. 01, 09 out. 2010. Disponível em:

https://acervo.folha.com.br/index.do. Acesso em: 07 out. 2019.

MORTOS na detenção podem superar 111. Folha de São Paulo, São Paulo, ano 72, n. 23.196, p. 01, 05 out. 1992. Acervo Folha. Disponível em: https://acervo.folha.com.br/index.do. Acesso em: 27 jul. 2019.

NO RIO número de mortes por policiais é recorde. Portal G1, Rio de Janeiro, 20 set. 2019. Disponível em: https://g1.globo.com/jornalnacional/noticia/2019/09/20/no-rio-numero-de-mortes-por-policiais-em-2019e-recorde.ghtml. Acesso em: 30 set. 2019.

PARA PRESIDENTE, ações são políticas de Estado. Folha de São Paulo, São Paulo, ano 82, n. 78.337, p. 04, 14 maio 2002. Disponível em: https://acervo.folha.com.br/index.do. Acesso em: 27 set. 2019.

PINHEIRO, Paulo Sérgio; MESQUITA NETO, Paulo. Programa Nacional de Direitos Humanos: avaliação do primeiro ano e perspectivas. Estudos Avançados, São Paulo, v. 30, n. 11, p. 117-134, 1997.

PINHEIRO, Paulo Sérgio. Autoritarismo e transição. Revista Usp, São Paulo, n. 09, p. 45-56, mar./abr. 1991.

PLANO de Direitos Humanos esbarra em base governista. Folha de São Paulo, São Paulo, ano 76, n. 24.513, p. 04, 14 mai. 1996. Acervo Folha. Disponível em: https://acervo.folha.com.br/index.do. Acesso em: 30 ago. 2019.

POLÍCIA DO RIO omite laudo sobre mortes. Folha de São Paulo, São Paulo, ano 
75, n. 24.144, ano 75, p. 06, 11 mai. 1995. Disponível em:

https://acervo.folha.com.br/index.do. Acesso em: 22 ago. 2019.

POLÍCIA INVADE favela e mata 14 pessoas. Folha de São Paulo, São Paulo, ano 75, n. 24.142, p. 04, 09 mai. 1995. Disponível em:

https://acervo.folha.com.br/index.do. Acesso em: 22 ago. 2019.

POLÍCIA MATA 13 em favela do Rio. Folha de São Paulo, São Paulo, ano 74, n. 23.940, p. 01, 19 out. 1994. Disponível em: https://acervo.folha.com.br/index.do. Acesso em: 22 ago. 2019.

POPULAÇÃO carcerária do Brasil é uma das maiores do mundo. Agência Brasil, Brasília, 07 nov. 2018. Disponível em:

http://agenciabrasil.ebc.com.br/geral/noticia/2018-11/populacao-carcerariafeminina-no-brasil-e-uma-das-maiores-do-mundo. Acesso em: 12 out. 2019.

QUADRILHAS criam "mercado" de matadores. Folha de São Paulo, São Paulo, ano 83, n. 27.344, p. C1, 26 out. 2003. Disponível em:

https://acervo.folha.com.br/index.do. Acesso em: 11 out. 2019.

RIOUX, Jean-Pierre. Pode-se fazer uma história do presente? In: CHAVEAU, Agnès; TÉTART, Philippe. Questões para a história do presente. Bauru: Edusc, 1999.

RODRIGUES, Fernando. Curto, médio ou longo? Folha de São Paulo, São Paulo, ano 76, n. 24.513, 14 mai. 1996. Disponível em:

https://acervo.folha.com.br/index.do. Acesso em: 26 ago. 2019

ROSANVALLON, Pierre. Por uma história do político. São Paulo: Alameda, 2010.

SANTOS, Mario Vitor dos. O massacre do Carandiru divide leitores. Folha de São Paulo, São Paulo, ano 72, n. 23.202, 11 out. 1992. Disponível em: https://acervo.folha.com.br/index.do. Acesso em: 26 ago. 2019.

SETOR agrícola condena decreto do presidente. Folha de São Paulo, São Paulo, ano 90, n. 29.500, p. A6, 08 out. 2010. Disponível em:

https://acervo.folha.com.br/index.do. Acesso em: 18 out. 2019.

SÓ 30\% das medidas são para este ano. Folha de São Paulo, São Paulo, ano 82, n. 78.337, p. C1, 14 maio 2002. Disponível em: https://acervo.folha.com.br/index.do. Acesso em: 27 set. 2019.

SOTELO, Ignacio. El estado social: antecedentes, origen, desarrollo y declive. Madrid: Editoral Trotta, 2010. 
STRECK, Lenio Luiz. Barganha penal que ameaça garantias é fast food processual. Consultor Jurídico, São Paulo, 10 jan. 2019. Disponível em: https://www.conjur.com.br/2019-jan-10/senso-incomum-barganha-penalameaca-garantias-fast-food-processual. Acesso em: 20 set. 2019.

SUWWAN, Leila. Apoio de FHC à união gay causa protestos. Folha de S. Paulo, São Paulo, ano 82, n. 79.242, 19 mai. 2002. Disponível em:

https://acervo.folha.com.br/index.do. Acesso em: 30 ago. 2019.

TESTEMUNHAS revelam o terror das milícias no Rio. PORTAL G1, Rio de Janeiro, 26 out. 2010. Disponível em: http://g1.globo.com/rio-de-janeiro/noticia/ 2010/10/ testemunhas-revelam-o-terror-das-milicias-no-rio.html. Acesso em: 16 out. 2019.

WACQUANT, Loïc. A aberração carcerária à moda francesa. Dados, Revista de Ciências Sociais, Rio de Janeiro, v. 47, n. 02, p. 215-232, 2004.

WACQUANT, Loïc. As prisões da miséria. Rio de Janeiro: Zahar, 2011.

WACQUANT, LoÏc. O lugar da prisão na nova administração da pobreza. Novos Estudos Cebrap, São Paulo, n. 80, p. 9-19, mar. 2008.

WACQUANT, Loïc. Castigar a los pobres: el gobierno neoliberal de la inseguridad social. Barcelona: Gedisa Editorial, 2009. 